\title{
An observational comparative study of clinical efficacy and safety of chlordiazepoxide and lorazepam in alcohol withdrawal syndrome
}

\author{
Nitishkumar D. Tank ${ }^{1}$, Bharti N. Karelia ${ }^{2}$, Nishant B. Bhansali ${ }^{3}$ \\ ${ }^{1}$ Dr Nitishkumar D Tank, Third year P.G. Student, ${ }^{2}$ Dr Bharti N. Karelia, Associate Professor, ${ }^{3}$ Dr Nishant B. Bhansali, \\ Assistant Professor, Department of Pharmacology, P.D.U. Government Medical College, Rajkot, Gujarat, India.
}

Address for Correspondence: Dr Nitishkumar D.Tank, Third year P.G. Student, Room No: 58, Department of Pharmacology, P.D.U. Government Medical College, Civil Hospital Campus, Jamnagar Road, Rajkot, Gujarat, India. Email: drnitishtank@gmail.com

\begin{abstract}
Background: Currently, Benzodiazepines like chlordiazepoxide, diazepam and lorazepam are the preferred drugs in the management of Alcohol withdrawal syndrome (AWS). These drugs of similar class are different in their pharmacokinetic profile which differently affect in AWS. Chlordiazepoxide is longer acting and converted to active metabolites in the liver, while lorazepam is shorter acting, with no active metabolites. Materials and methods: An observational, prospective and comparative study conducted in 100 patients of AWS. They received either Chlordiazepoxide or Lorazepam and divided into two comparison groups at the screening. Observation was started from day of admission to every day till day of discharge. The initial withdrawal assessment and subsequent changes in withdrawal during treatment were assessed using the Clinical Institute Withdrawal Assessment for Alcohol scale, revised (CIWA-Ar) in both the groups. Clinical global impression (CGI) score was also used to evaluate drug efficacy in both the groups. Details of adverse drug reactions, if any appear were recorded. Results: CIWA-Ar score, CGI-Severity (CGI-S) score and CGI-Improvement (CGI-I) score showed statistically significant difference between two groups. But percentage reduction in CIWA-Ar, CGI-S and CGI-I score were almost similar in both groups. Intra group comparison at different duration of treatment progressed and in between days of treatment there was statistically significant reduction of these scores. Considering no. of adverse events, reported adverse events causality, severity, predictability and preventability assessment, both drugs were safe. Conclusion: Both the drugs had almost similar efficacy in terms of to reduce CIWAAr score, CGI-S score, CGI-I score and similar safety profile.
\end{abstract}

Key words: Chlordiazepoxide, Lorazepam, Alcohol, Alcohol withdrawal syndrome, CIWA-Ar, CGI.

\section{Introduction}

Alcohol is a psychoactive substance with dependence producing properties that has been widely used in many cultures for centuries. The harmful use of alcohol is a causal factor in more than 200 diseases \& injury conditions [1]. According to World Health Organization Global status report on alcohol and health 2014, in 2010 $47.7 \%$ males and $28.9 \%$ females globally were current drinkers among total population of aged 15 years and older [2]. As per WHO $1 / 4$ to $1 / 3$ of male population drink alcohol in India and neighboring south Asian countries and also the use amongst women in increasing [3].

Manuscript received $4^{\text {th }}$ August 2016

Reviewed: $15^{\text {th }}$ August 2016

Author Corrected: $25^{\text {th }}$ August 2016

Accepted for Publication $10^{\mathrm{th}}$ September 2016
Alcohol Withdrawal Syndrome (AWS) is a potentially life threatening condition that can occur in people who have been drinking heavily for weeks, months or years and then either stop or significantly reduce their alcohol consumption [4].

The symptoms range from minor ones such as insomnia and tremulousness to severe complications such as withdrawal seizures and delirium tremens [5]. Because alcohol withdrawal symptoms can rapidly worsen it is important to seek medical attention even if symptoms are seemingly mild [4]. The effective management of AWS includes a combination of supportive and pharmacological measures. 
Currently, benzodiazepines like chlordiazepoxide, diazepam and lorazepam are the preferred drugs in the management of alcohol withdrawal symptoms.

While the first two drugs are long-acting, lorazepam is intermediate-acting. Both chlordiazepoxide and diazepam are time-tested choices to treat alcohol withdrawal.

However, they are metabolized by the hepatic enzymes, and also form active metabolites that accumulate in the liver. On the contrary, lorazepam is less likely to accumulate in the liver, because it is metabolized by conjugation, a pathway that is less affected than the hepatic microsomal pathways in liver dysfunction.

Additionally, lorazepam has no active metabolites. It is preferred in the management of alcohol withdrawal, especially in those with alcoholic liver disease [6].

Currently, searching the literature we find very few head-to-head trials comparing chlordiazepoxide with lorazepam [6, 7, 8, 9] Therefore, the current study was undertaken to compare the safety and efficacy of chlordiazepoxide and lorazepam in individuals with alcohol withdrawal symptoms.

\section{Material and Methods}

Study populations: Patients above the age of 18 years with uncomplicated alcohol withdrawal syndrome admitted to in-patient wards, Departments of Psychiatry at a Teaching hospital from January 2014 to July 2015 were included in the study.

Ethical clearance was obtained from the Institutional Ethics Committee. Inclusion criteria: (1) Patient meeting criteria for alcohol withdrawal according to DSM-5 (2) Must be medically stable. Exclusion criteria: (1) Patients with delirium tremens, psychiatric comorbidity, renal or cardiovascular diseases (2) Patients dependent on any substance other than nicotine (3) Patients with multidrug abuse (4) Contraindications for the use of either of the study medication.

\section{Method}

This was an observational, prospective and comparative study conducted in total 100 patients of AWS. Informed consent in written was obtained from patients selected on the basis of inclusion and exclusion criteria before the enrolment into the study as participant. They received either Chlordiazepoxide or Lorazepam and divided into two comparison groups at the screening. Observation was started on day-1 of starting of treatment. Follow up was carried out every day till day of discharge. A suitable case record form was designed to record the all necessary and relevant information (Patient demographic details, disease related history, alcohol consumption details, details of investigation and detailed treatment history).

The initial withdrawal assessment and subsequent changes in withdrawal during treatment were assessed using the Clinical Institute Withdrawal Assessment for Alcohol scale, revised (CIWA-Ar) [19] in both the groups. Clinical global impression (CGI) score [20] was also used to evaluate drug efficacy in both the groups. Details of adverse drug reactions, if any appear were recorded.

Statistical analysis: Recorded data were analyzed by Microsoft Office Excel 2007 and Graph Pad Prism 6 for windows, version 6.07. Age, alcohol related information (Last intake \& Abstinence) and liver function test results between two groups were compared by Mann-Whitney test. CIWA-Ar score, CGI-Severity and CGI-Improvement score between two groups at different days were compared by Mann-Whitney test. For intra group comparison of these scoring Friedman test was used.

Scoring difference in between days of treatment Posthoc test: Dunn's multiple comparison tests were used. The $\mathrm{P}$ value $<0.05$ was considered as significant.

Fisher's exact test was used in the statistical analysis of the adverse drug reaction. The $\mathrm{P}$ value $<0.05$ was considered as significant.

\section{Results}

Out of 100 patients 38 patients had received chlordiazepoxide and 62 patients had received lorazepam. Majority of patients were male and most of the patients were in the age group of 30-39 years in both groups. Majority of patients had last intake of alcohol in number of pouches was in range of 4-7 and 1-3 in chlordiazepoxide and lorazepam group respectively (Quantity of alcohol in 1 pouch: $200 \mathrm{ml}$ ). Majority of patients in both groups had abstinence of alcohol in number of days was in the range of 0-3 days. 
As shown in table 1, there was no significant difference between the treatment groups in terms of age, last intake of alcohol, abstinence and admission day liver function tests (LFTs) results.

Table-1: Age, Alcohol history (last intake, abstinence) and admission day LFTs results of patients.

\begin{tabular}{|c|c|c|c|c|}
\hline \multirow{2}{*}{ Parameter } & Unit & $\begin{array}{c}\text { Chlordiazepoxide } \\
(\mathbf{n = 3 8}) \\
(\mathbf{m e a n} \pm \mathbf{S D})\end{array}$ & $\begin{array}{c}\text { Lorazepam } \\
(\mathbf{n = 6 2}) \\
(\mathbf{m e a n} \pm \mathbf{S D})\end{array}$ & P value \\
\hline Age & Years & $37.26 \pm 8.77$ & $37.96 \pm 9.16$ & 0.8136 \\
\hline Last intake & No. of pouches & $4.42 \pm 2.85$ & $4.61 \pm 2.87$ & 0.8457 \\
\hline Abstinence & No. of days & $2.15 \pm 2.32$ & $2.37 \pm 2.52$ & 0.7322 \\
\hline ALP & IU/L & $138.28 \pm 67.78$ & $136.43 \pm 64.97$ & 0.5891 \\
\hline ALT & IU/L & $51.08 \pm 27.49$ & $46.80 \pm 34.89$ & 0.2042 \\
\hline Billirubin Direct & $\mathrm{mg} / \mathrm{dl}$ & $0.52 \pm 0.29$ & $0.50 \pm 0.25$ & 0.6327 \\
\hline Billirubin Total & $\mathrm{mg} / \mathrm{dl}$ & $1.08 \pm 0.60$ & $1.04 \pm 0.52$ & 0.3966 \\
\hline
\end{tabular}

$P$ value $<0.05$ considered as significant

Considering efficacy, as shown in table 2, at baseline, mean total CIWA- Ar score was significantly higher in chlordiazepoxide group $(43.53 \pm 6.43)$ than lorazepam group $(40.82 \pm 6.01)$. Third day and fifth day (last day) CIWA-Ar score was also significantly higher in chlordiazepoxide group. At the ends of third day and fifth day (last day), percentage decrease in mean score were $46 \%$ and $79 \%$ in chlordiazepoxide group and $50 \%$ and $83 \%$ in lorazepam group. Baseline and third day CGI-Severity (CGI-S) score shows that difference between two groups was not significant. But fifth day CGI-Severity score showed that it was significantly higher in chlordiazepoxide group. At the ends of third day and fifth day, percentage decrease in mean score was 35\% and $70 \%$ in chlordiazepoxide group and $34 \%$ and $75 \%$ in lorazepam group. At baseline, mean total of CGI-Improvement (CGI-I) score was not measured in both groups. Third day and fifth day CGI-Improvement score showed that it was significantly higher in chlordiazepoxide group. From third day to fifth day of treatment, percentage decreases in mean score were $51 \%$ in chlordiazepoxide group and $52 \%$ in lorazepam group.

Table-2: CIWA-Ar, CGI-S and CGI-I Score comparison between two groups.

\begin{tabular}{|c|c|c|c|c|c|c|}
\hline Scale & $\begin{array}{c}\text { Day of } \\
\text { treatment }\end{array}$ & $\begin{array}{c}\text { Chlordiazepoxide } \\
\text { (mean } \pm \text { SD) }\end{array}$ & $\begin{array}{c}\text { \% decrease } \\
\text { in mean } \\
\text { score }\end{array}$ & $\begin{array}{c}\text { Lorazepam } \\
\text { (mean } \pm \text { SD) }\end{array}$ & $\begin{array}{c}\text { \% decrease } \\
\text { in mean } \\
\text { score }\end{array}$ & P value \\
\hline \multirow{2}{*}{ CIWA-Ar } & Day-1 & $43.53 \pm 6.43$ & 0 & $40.82 \pm 6.01$ & 0 & 0.0458 \\
\cline { 2 - 7 } & Day-3 & $23.45 \pm 5.26$ & $46 \%$ & $20.61 \pm 6.22$ & $50 \%$ & 0.0020 \\
\cline { 2 - 7 } & Day-4/5 & $9.03 \pm 3.98$ & $79 \%$ & $6.95 \pm 3.88$ & $83 \%$ & 0.0050 \\
\hline \multirow{2}{*}{ CGI-S } & Day-1 & $5.74 \pm 0.55$ & 0 & $5.56 \pm 0.59$ & 0 & 0.0981 \\
\cline { 2 - 7 } & Day-3 & $3.74 \pm 0.50$ & $35 \%$ & $3.69 \pm 0.53$ & $34 \%$ & 0.6745 \\
\cline { 2 - 7 } & Day-4/5 & $1.74 \pm 0.76$ & $70 \%$ & $1.42 \pm 0.59$ & $75 \%$ & 0.0381 \\
\hline \multirow{2}{*}{ CGI-I } & Day-1 & 0 & 0 & 0 & 0 & $>0.9999$ \\
\cline { 2 - 7 } & Day-3 & $2.71 \pm 0.61$ & 0 & $2.34 \pm 0.51$ & 0 & 0.0025 \\
\cline { 2 - 7 } & Day-4/5 & $1.34 \pm 0.48$ & $51 \%$ & $1.13 \pm 0.34$ & $52 \%$ & 0.0135 \\
\hline
\end{tabular}

$\mathrm{P}$ value $<0.05$ considered as significant

Intra (within) group comparison of CIWA-Ar score, CGI-S score and CGI-I score at different duration of treatment progress (Freidman test; $\mathrm{P}$ value $<0.0001$ ) as shown in Figure 1, 2 and 3 shows that as the duration of treatment progress, there was significant decrease in scores. 

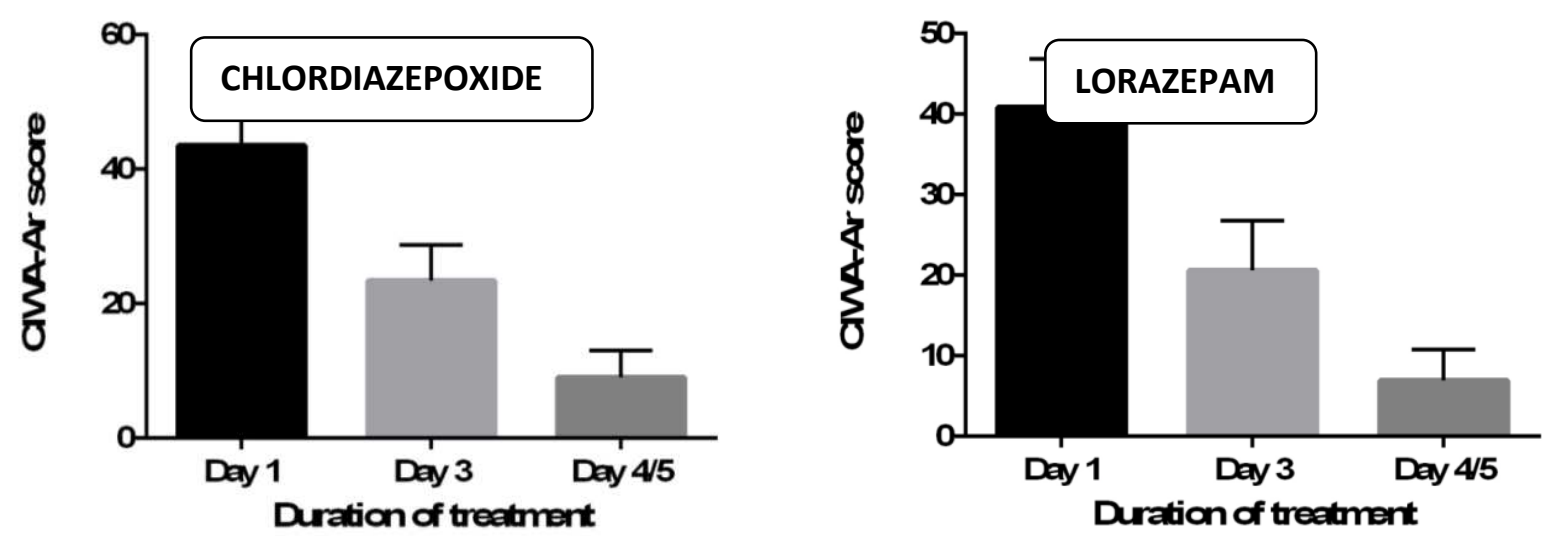

Figure-6: Intra group comparison of CIWA-Ar score in Chlordiazepoxide and lorazepam treated patients.
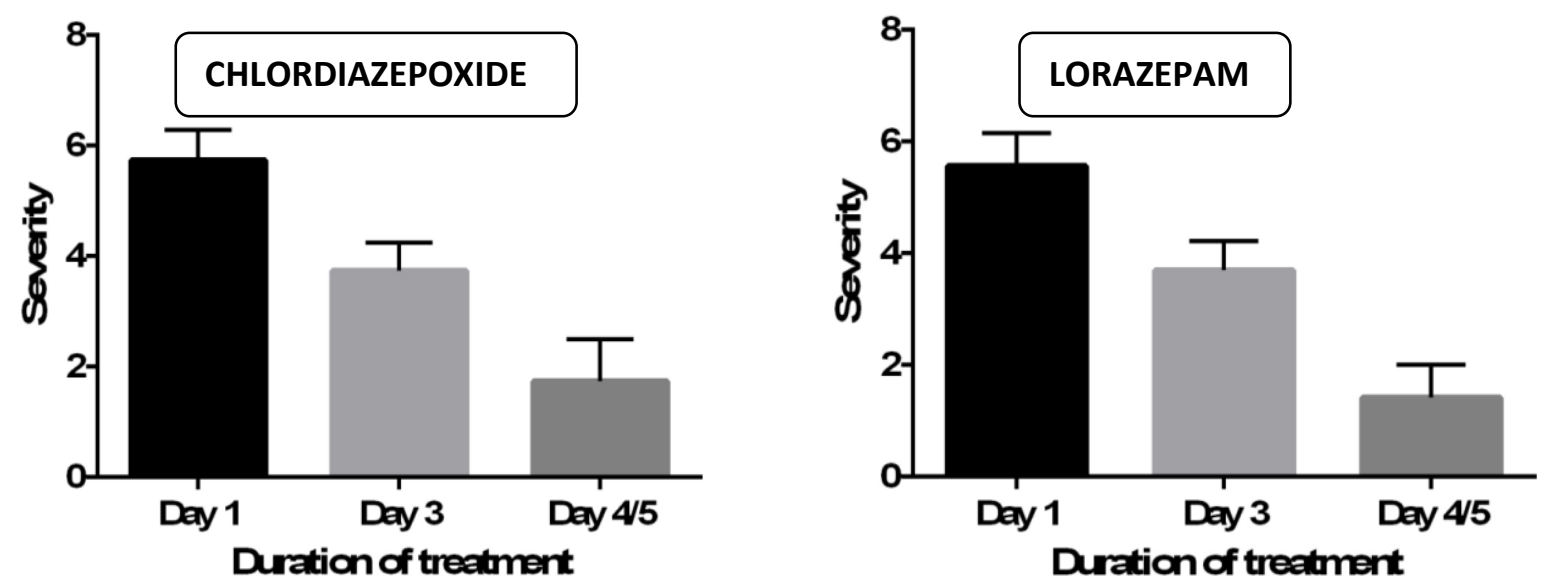

Figure-2: Intra group comparison of CGI-Severity score in Chlordiazepoxide and lorazepam treated patients.
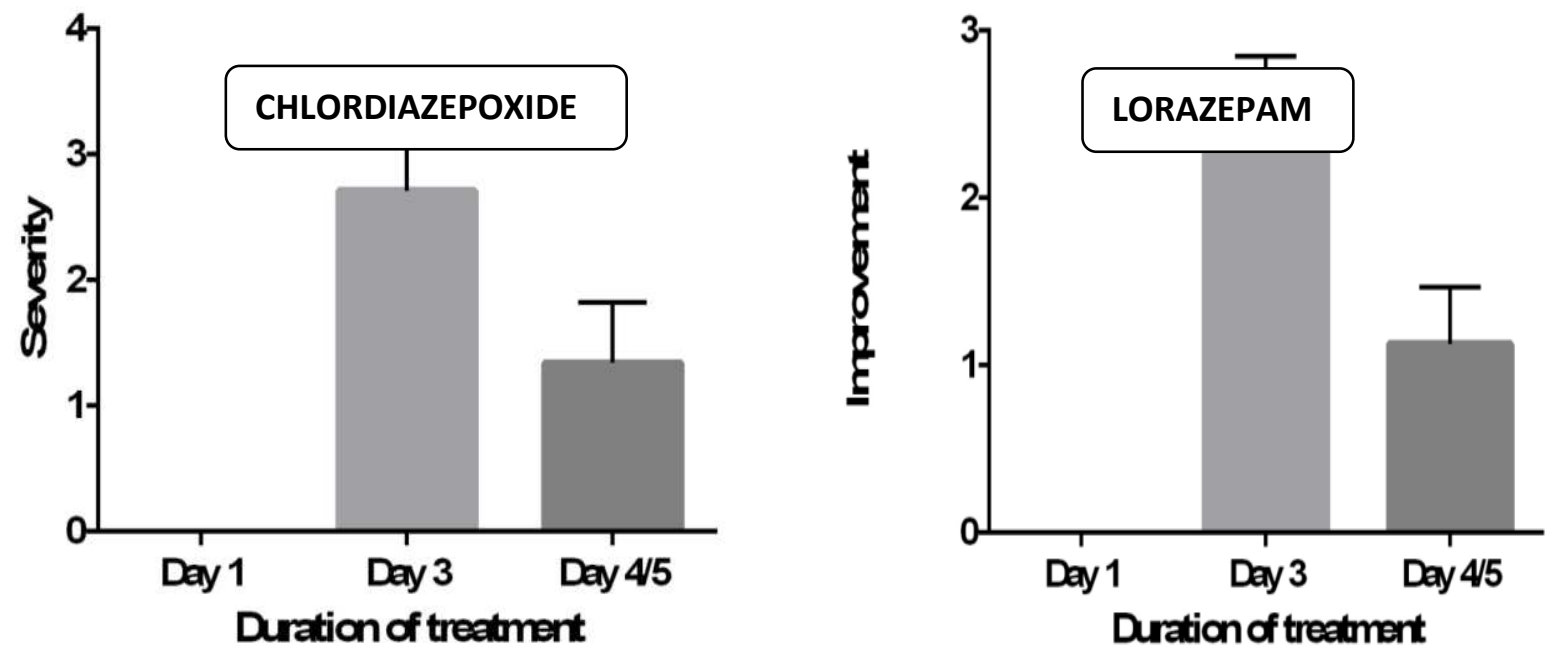

Figure-3: Intra group comparison of CGI-Improvement score in Chlordiazepoxide and lorazepam treated patients. 
Comparison of duration of treatment progress in terms of within group CIWA-Ar score, CGI-S score and CGI-I score between days of treatment (Post hoc test: Dunn's multiple comparisons between day 1 vs. day 3, day 1 vs. day 4/5 and day 3 vs. day 4/5) in both groups, showed that the differences were statistically significant.

Regarding safety point of view, there was no any serious adverse events were reported in either group. Patients with adverse events in chlordiazepoxide and lorazepam groups were $4(10.53 \%)$ and $5(8.06 \%)$ respectively. There was no statistical significant difference between two groups regarding no. of adverse events reported (Fisher's exact test, P value: 0.7274 ). There was no any treatment or drug discontinuation due to any adverse events (including serious) in either groups. [Table 3].

Table-3: Safety profile comparison between groups.

\begin{tabular}{|c|c|c|c|}
\hline Safety profile & Chlordiazepoxide $(\mathbf{n = 3 8})$ & $\begin{array}{c}\text { Lorazepam } \\
(\mathbf{n = 6 2})\end{array}$ & P value \\
\hline $\begin{array}{c}\text { Serious adverse events } \\
\text { (SAEs) }\end{array}$ & 0 & 0 & 0.7274 \\
\hline $\begin{array}{c}\text { Adverse events (AEs) } \\
\text { Discontinuation due to any } \\
\text { AEs or SAEs }\end{array}$ & $4(10.53 \%)$ & 0 & \\
\hline
\end{tabular}

$\mathrm{P}$ value $<0.05$ considered as significant

An adverse event, dizziness was reported in one patient (1.61\%) of lorazepam group. Sleepiness was reported in three patients $(7.89 \%)$ and one patient $(1.61 \%)$ of chlordiazepoxide and lorazepam group respectively. Sedation was reported in one patient $(2.63 \%)$ and three patients $(4.84 \%)$ in chlordiazepoxide and lorazepam group respectively.

Considering causality, all the adverse drug reactions were 'possible' according to World Health Organization Uppsala Monitoring Centre, causality assessment criteria and by Naranjo's adverse drug reaction causality scale. All the adverse drug reactions were mild (Level-1) in severity according to Hartweig severity scale, probably preventable according to modified Schumock and Thronton preventability scale and predictable.

\section{Discussion}

Since their introduction in the 1960s, benzodiazepines have stood the test of time and are the first-line treatments for AWS. Characteristics of the individual agents vary significantly in terms of rapidity of onset, different metabolic profile and duration of action. But, meta-analyses showed no differences in relative efficacies of different benzodiazepines in AWS (MayoSmith 1997; Ntais et al. 2005) [10]. Contradictory to result of meta-analysis, the use of one benzodiazepine over another is a subject of debate [11]. Here, we did observational comparative study between long acting chlordiazepoxide with intermediate acting lorazepam in regards to their clinical efficacy and safety in AWS patients.

All patients were male but there was no any predilection to include only male patients. This result revealed the bitter truth of India, where the number of women afflicted by alcoholism is rising alarmingly but due to stigma and non acceptance from family and society not letting them get help. Majority of the patients in our study was in the age group of 30-39 years. A study conducted by Ramanujam R. et al showed that most of the patients were in the range of 28-47 years [6]. As per table 1 , mean age of the patients in our study was $37.7 \pm$ 9.0 years. A study conducted by Chourishi A. et al showed that mean age of the patient was $38.37 \pm 8.00$ years [12]. Majority of patients had last intake of alcohol in chlordiazepoxide group $(44.74 \%)$ was in range of 800-1400 $\mathrm{ml}(884 \mathrm{ml})$ and for lorazepam group (48.39\%) was $200-600 \mathrm{ml}(922 \mathrm{ml})$. A study conducted by Ramanujam R. et al showed that average alcohol consumption in the chlordiazepoxide and Lorazepam groups was in range of $180-1540 \mathrm{ml}(534.37 \mathrm{ml})$ and $180-1080 \mathrm{ml}(444 \mathrm{ml})$ respectively [6]. Majority of patients in chlordiazepoxide group (89.47\%) and lorazepam group $(83.87 \%)$ had abstinence in range of 0-3 days. As per table 1, average duration of abstinence 
in chlordiazepoxide group was $2.15 \pm 2.32$ days and in lorazepam group it was $2.37 \pm 2.52$ days. A study conducted by Ramanujam R. et al showed that the last drink consumed was $<12$ hours ago in majority of patients [7]. Temporal relations exist between cessation of alcohol intake and the onset of withdrawal symptoms [13]. Mild withdrawals usually occur within 24 hours, Moderate withdrawal usually occurs 24-36 hours after and severe withdrawal usually occurs more than 48 hours after a cessation or decrease in alcohol consumption [14].

LFT was performed at baseline as a screening test to detect liver pathology, but it was not repeated at the end of treatment. This is because it takes about three months to observe any significant change in the liver function tests [6]. Study done by Nyblom H. et al showed that abnormal results of liver function tests may indicate advanced alcoholic liver disease rather than heavy drinking [15]. As per Table 1, there was no stistically significant difference in baseline LFT results between two groups. A study done by Ramanujam R. et al showed that there was no significant difference in the various parameters of LFT at baseline as well as at the end of the study period [6].

To check efficacy of drugs in our study we had used CIWA-Ar scale and CGI scale (CGI-S and CGI-I). Similar scales were used to check efficacy in a study conducted by Chourishi A. et al. [12] CIWA-Ar is a 10item validated scale, used to quantify the severity of AWS and to monitor and medicate patients going through withdrawal. CIWA-Ar scores below 10 are considered mild withdrawal; between 10 and 20 are moderate withdrawal, and above 20 are considered severe withdrawal [10]. The maximum score is 67 and those with a score less than 10 do not require additional medications for withdrawal [6].

As per Table 2, CIWA-Ar score in chlordiazepoxide group was higher than lorazepam group from baseline to end of treatment. The difference exists was statistically significant might be not clinically. Because baseline CIWA-Ar score was above 20 in both groups and patients were suffering from severe alcohol withdrawal. At the end of treatment score was below 10 and patients in both groups came under mild alcohol withdrawal syndrome. Study conducted by Ramanujam R. et al showed that CIWA-Ar score at baseline and throughout the study period were similar in chlordiazepoxide and lorazepam groups, with no significant difference exists between them [6]. Percentage reductions of mean CIWA-Ar score from baseline to at the end of treatment showed that there was no significant difference between two drugs. Similar result of no significant difference between two drugs in percentage reduction of severity was found in a study conducted by Ramanujam R. et al. [6]. As per Figure 1, intra group comparison of CIWA-Ar score at different duration of treatment progress showed that there was statistically significant decrease in CIWA-Ar score and in between days of treatment (day 1 vs. day 3, day 1 vs. day 4/5 and day 3 vs. day 4/5) difference in CIWA-Ar score were statistically significant. Similar result of intra group comparison was seen in a study conducted by Ramanujam R. et al. [6] so, inter group and intra group comparison of CIWA-Ar score between chlordiazepoxide and lorazepam revealed almost similar efficacy.

In our study, duration of treatment was found 5 days (in some patients it was 4 days) because at the end of that duration patients suffered from mild withdrawal. Literature search showed that patient suffering from mild withdrawal (CIWA-Ar $<10$ score) does not require pharmacological intervention $[11,16]$. Contradiction to this claim was seen in a study conducted by Ramanujam R. et al in which CIWA-Ar score was below 10 at the end of fifth day but patient was drug free after 8 days [6].

Other efficacy scale, CGI has two components-the CGI-S, which rates illness severity, and the CGI-I, which rates change from the initiation (baseline) of treatment. Both components of scale are based on seven point score. The CGI-I score generally tracks with the CGI-S such that improvement in one follows the other. Consequently, the two CGI scores can occasionally be dissociated such that a clinician may notice changes in the CGI-I relative to baseline despite no recent changes in the overall CGI severity score or vice versa [17].

In our study, CGI-S and CGI-I scoring was done on basis of guidelines which were used as suggestions, not absolute for scoring [17]. As per Table 2, at base line CGI-Severity score in chlordiazepoxide group was similar to lorazepam group and difference was not statistically significant between two groups. Clinically we could interpret that, patients in both groups were markedly (CGI-S: 5) or severely ill (CGI-S: 6) at base line. Score 5 means patients was suffering from 
intrusive symptoms of alcohol withdrawal that distinctly impair social / occupation function or cause intrusive level of distress. Score 6 means patients behaviour and function were frequently influenced by withdrawal symptoms and may required assistance from others [17]. At $3^{\text {rd }}$ day, score was near 4 in both groups and no statistically significant difference was found between them. Clinically we could interpret that, patients in both groups were moderately ill, that means symptoms of alcohol withdrawal were causing noticeable but modest functional impairment or distress which possibly warrant medications [17]. At the end of treatment, severity score in chlordiazepoxide group was higher than lorazepam group, which was statistically significant. Score was close to 2 in chlordiazepoxide group and close to 1 in lorazepam group. Clinically we could interpret that, patients were borderline ill (subtle symptoms of withdrawal) in chlordiazepoxide group and normal not at all ill (no symptoms of withdrawal) in lorazepam group [17].

As per table 2, CGI-I scores of $3^{\text {rd }}$ day and end of treatment day were higher in chlordiazepoxide group than lorazepam group, which were statistically significant. At $3^{\text {rd }}$ day score was close to 3 in chlordiazepoxide group and close to 2 in lorazepam group. At the end of treatment score of lorazepam group was very close to 1 than chlordiazepoxide group. Clinically we could interpret that at $3^{\text {rd }}$ day patients in chlordiazepoxide group minimally improved, that means slightly better with little or no clinically meaningful reduction of symptoms. It represents very little change in basic clinical status, level of care or functional capacity. In lorazepam group much improved, which means notably better with significant reduction of symptoms, increase in the level of functioning but some symptoms remain. At the end of treatment, improvement in patients of lorazepam group was higher than chlordiazepoxide group. Patients were very much improved means nearly all better, minimal symptoms and showed good level of functioning [17].

As per Figure 2 and 3, intra group comparison of CGI-S and CGI-I score at different duration of treatment progress showed statistically significant decrease in score and in between days of treatment (day 1 vs. day 3 , day 1 vs. day 4/5 and day 3 vs. day 4/5) difference was statistically significant. Overall, CGI-S and CGI-I at the end of treatment statistically showed that reduction in severity of symptoms with improvement in patient's withdrawal condition was significantly higher in lorazepam group. But percentage reduction in severity with percentage improvement in patient's withdrawal condition showed that both drug had almost similar efficacy in regards to CGI score.

Regarding safety point of view, as per table 3, there were no any SAEs and any drug discontinuation due to adverse events founded in either group. The psychiatrist was free to prescribe additional dosage according to severity of symptoms and on clinical judgment in our study, this higher dose prescribed patients showed adverse events in both groups. There was no statistically significant difference between two groups regarding no. of adverse events reported. Reported adverse events were dizziness, sleepiness and sedation; which were common with benzodiazepines. Study done by Solomon J. et al showed no drug related adverse effects during treatment [18]. Sometimes patient develop withdrawal symptoms after stopping the benzodiazepines. Study conducted by Kumar C. et al showed no any withdrawal complications after stopping both the drugs [7]. Another study done by Ramanujam R. et al showed no any adverse events by both the drugs during the treatment or after stopping the medications [6]. Considering no. of adverse events, reported adverse events causality, severity, predictability and preventability assessment and literature search we could say both the drugs were safe in alcohol withdrawal treatment.

Literature search showed similar studies comparing chlordiazepoxide and lorazepam in alcohol withdrawal syndrome patients. Studies done by Ramanujam R. et al, Kumar C. et al and Solomon J. et al concluded that lorazepam was as effective as the more traditional drug chlordiazepoxide in treatment of alcohol withdrawal syndrome $[6,7,18]$ Study done by Rajmohan V. et al showed superiority of lorazepam over chlordiazepoxide in treatment of alcohol withdrawal syndrome [9].

Limitations of our study were, it was open blind, unicentric and had small sample size which was unequally distributed among both groups. Reason of unequal distribution might be as it was an observational study not a randomized controlled trial. Also, Majority of the patients admitted for withdrawal treatment belongs to lower socio economic class so they were treated with lorazepam because it is included in our hospital formulary. Clinical interpretation of patients conditions according to CIWA- Ar and CGI score based on statistical variables (mean $\pm \mathrm{SD}$ ). So, we could not 
say with confidence that results which were statistically significant showed clinical significance and vice versa. As there was no longer stay of patients after stopping the treatment we could no judge either patient developed withdrawal symptoms of benzodiazepines or not.

Directions for future research include the continued search for non-BZ treatments for AWS. Research has not been conducted to determine specific AWS strategies for geriatric, pregnant, or medically ill populations so it is also area of future research.

\section{Conclusion}

From above study, concluded that both the drugs chlordiazepoxide and lorazepam had almost similar efficacy in terms of to reduce CIWA-Ar score, CGI-S score, CGI-I score and similar safety profile in treatment of alcohol withdrawal syndrome.

Funding: Nil, Conflict of interest: None initiated, Permission from IRB: Yes

\section{References}

1. World Health Organization. Alcohol fact sheet. [Online] 2015. [cited 2015 Sep 24]; Available from: URL: www.who.int/mediacentre/factsheets/fs349/en/

2. World Health Organization. Global status report on alcohol and health, 2014. [Online] 2014. [cited 2015 Sep 24]; Available from: URL:www.who.int/substance .../global_alcohol_report/msb_gsr_2014_3.pdf.

3. Alcohol use disorder. National Health Portal. [Online]; Available from: URL:http://www.nhp.gov. in/ healthlyliving / alcohol-use-disorder.

4. Alcohol withdrawal. WebMD. [Online] 2015. [cited 2015 Sep 24]; Available from: URL: www.webmd.com /mental.../alcohol-withdrawal-symptoms-treatments.

5. Bayard M, Mclntyre J, Hill KR, Woodside J Jr. Alcohol withdrawal syndrome. Am Fam Physician. 2015; 69 (6):1443-50. Available from: URL: http:// www.aafp.org/afp/2004/0315/p1443.html

6. Ramanujam R, L P, G S, Thimmaiah RS. A comparative study of the clinical efficacy and safety of Lorazepam and chlordiazepoxide in alcohol dependence syndrome. J Clin Diagn Res. 2015 Mar;9(3):FC10-3. doi: 10.7860/JCDR/2015/11887.5678. Epub2015Mar 1.
7. Kumar CN, Andrade C, Murthy P. A randomized, double-blind comparison of lorazepam and chlordiazepoxide in patients with uncomplicated alcohol withdrawal. J Stud Alcohol Drugs. 2009 May;70(3):467-74.

8. Miller WC Jr, McCurdy L. A double-blind comparison of the efficacy and safety of lorazepam and diazepam in the treatment of the acute alcohol withdrawal syndrome. Clin Ther. 1984; 6(3): 364-71.

9. Rajmohan V, Sushil K, Mohandas E. A double blind randomised comparison of chlordiazepoxide and lorazepam in alcohol withdrawal. Asian J Psychiatr. 2013 Oct;6(5):401-3. doi: 10.1016/j.ajp.2013.05. 003. Epub 2013 Jun 13.

10. Haber $\mathrm{P}$, Lintzeris $\mathrm{N}$, Proude E, Lopatko O. Guidelines for the treatment of alcohol problems. [Online]. 2009 [cited 2015 Sep 26]; Available from: URL: http:// www. drugsandalcohol. ie/ 20201/1/ Gudelines_for_treatment_of_alcohol_problems.pdf

11. Department of Surgical education, Orlando regional medical center guideline for Alcohol withdrawal. [Online]. 2009 [cited 2015 Sep 27]; Available from: URL:http://www.surgicalcriticalcare.net/Guidelines/Alc ohol\%20withdrawal\%202015.pdf

12. Chourishi A, Raichandani O, Chandraker S, Chourishi S. A comparative study of efficacy \& tolerability of lorazepam and gabapentin in the treatment of alcohol withdrawal syndrome. Int J Pharm Sci Rev Res. 2010; 3(2):80-84. Available from: URL: http://www.globalresearchonline.net/journalcontents/Vo lume3issue2/Article\%20014.pdf

13. Kattimani S, Bharadwaj B. Clinical management of alcohol withdrawal: A systematic review. Ind Psychiatry J. 2013 Jul;22(2):100-8. doi: 10.4103/09726748.132914.

14. McKeon A Frye MA, Delanty N. The alcohol withdrawal syndrome. J Neurol Neurosurg Psychiatry. 2008 Aug;79(8):854-62. Epub 2007 Nov 6.

15. Nyblom H, Berggren U, Balldin J, Olsson R. High AST/ALT ratio may indicate advanced alcoholic liver disease rather than heavy drinking. Alcohol \& Alcoholism. 2004; 39(4): 336-339. 
16. Maldonado JR. An approach to the patient with substance use and abuse. Med Clin North Am. 2010 Nov; 94 (6):1169 - 205, x-i. doi: 10.1016/j. mena. 2010.08.010.

17. Busner J, Targum SD. The Clinical Global Impressions Scale: Applying a research tool in clinical practice. Psychiatry (Edgmont). 2007; 4(7): 28-37.

18. Solomon J, Rouck LA, Koepke HH. Double-blind comparison of lorazepam and chlordiazepoxide in the treatment of the acute alcohol abstinence syndrome. Clin Ther. 1983;6(1):52-8.

19. Clinical Institute Withdrawal Assessment of Alcohol Scale, Revised. Pdf [Online]; Available from: URL: https://umem.org/files/uploads / 1104212257 CIWA-Ar.pdf

20. Clinical Global Impression (CGI) Scale. pdf [Online]; Available from: URL: http: // www. psywellness.com.sg/docs/CGI.pdf

\section{How to cite this article?}

Nitishkumar D. Tank, Bharti N. Karelia, Nishant B. Bhansali. An observational comparative study of clinical efficacy and safety of chlordiazepoxide and lorazepam in alcohol withdrawal syndrome. Int J Med Res Rev 2016;4(9):16461654.doi:10.17511/ijmrr. 2016.i09.23. 